\title{
AVALIAÇÃO DE CULTIVARES DE CEBOLA EM DIFERENTES ÉPOCAS DE SEMEADURA EM MONTE ALEGRE DO SUL ( $\left.{ }^{1}\right)$
}

\author{
ROGÉRIO SALLES LISBÃO $\left({ }^{2}, 5\right)$, JOÃO BAPTISTA FORNASIER $\left({ }^{2,}, 5\right)$, \\ TOSHIO IGUE $\left({ }^{3}, 5\right)$ e ALUISIO PADILHA CURY $\left({ }^{4}\right)$
}

\begin{abstract}
RESUMO
Objetivando fornecer aos produtores opções à utilização de novos cultivares em período mais amplo de plantio, desenvolveu-se um experimento na Estaçâo Experimental de Monte Alegre do Sul (SP) (22 $42^{\circ}$ 'S), onde foram avaliadas duas introduçoes de cebola (Allium cepa L.) cultivares Crioula e Valencianita San Juan, em quatro épocas de semeadura, a saber: março, abril, maio e junho. Verificou-se que a época de semeadura influenciou a produtividade e o peso médio de bulbos comerciáveis, nos dois cultivares. O 'Crioula' superou 'Valencianita San Juan' em produtividade e peso médio de bulbos comerciáveis, nas semeações de março e abril, não havendo, no entanto, diferença nas semeaçós mais tardias. Quanto à produção de bulbos múltiplos e tipo "charuto", o 'Valencianita San Juan' apresentou maior porcentagem nas quatro épocas de semeadura. $O$ 'Crioula' mostrou-se sensível ao florescimento prematuro somente na semeadura de março. Em relação às características estudadas, portanto, nas condiçðes edafoclimáticas de Monte Alegre do Sul, é sugerida a utilização do 'Crioula' com semeação em abril, e do 'Valencianita San Juan' em maio. Houve diminuição do ciclo dos cultivares à medida que se atrasou a semeação.
\end{abstract}

Termos de indexação: cebola; Allium cepa L.; cultivares; épocas de semeadura.

( ${ }^{1}$ ) Trabalho apresentado no XXIII Congresso Brasileiro de Olericultura, realizado no Rio de Janeiro, 18-23 de julho de 1983. Recebido para publicação em 21 de fevereiro de 1984. nas (SP).

${ }^{2}$ ) Seçāo de Hortaliças Diversas, Instituto Agronômico (IAC), Caixa Postal 28, 13100 - Campi-

$\left({ }_{4}^{3}\right)$ Seçāo de Técnica Experimental e Cálculo, IAC.

(4) Engenheiro-Agrônomo, estagiário da Seção de Hortaliças Diversas, IAC.

( ${ }^{5}$ ) Com bolsa de suplementação do CNPq. 


\section{INTRODUÇÃô}

A cebola (Allium cepa L.) é uma das espécies hortícolas de maior expressão econômica no País e no Estado de São Paulo, que participou com $38 \%$ da produção nacional em 1982 (ANUARIO, 1982). Os municípios paulistas que mais contribuíram para essa produção foram Piedade, Pilar do Sul, São José do Rio Pardo e Monte Alto, onde são cultivados principalmente cultivares de cebolas claras precoces e baias piriformes, em distintos sistemas e periodos de semeação.

O município de Monte Alegre do Sul, embora não seja tradicional produtor de cebola, reúne condições climáticas favoráveis à cultura, e assim informações aí obtidas podem servir a outras áreas de ecologia similar. Sua produção de cebola se dá durante o inverno, utilizando principalmente cultivares do tipo baia piriforme. No entanto, tanto a produtividade como a qualidade da cebola cultivada em Monte Alegre do Sul ainda estão abaixo dos padrões desejáveis. Entre os fatores que contribuem para essa deficiência, destaca-se o desconhecimento da melhor época de semeadura para cada cultivar, nas condições locais.

Entre os trabalhos de pesquisa conduzidos envolvendo épocas de plantio e comportamento de variedades nas condições climáticas paulistas, destacam-se os de BIANCHI (1962), CAMPOS et alii $(1969,1975)$, CAMPOS \& IGUE (1972, 1975), CHURATA-MASCA (1975) e CHURATA-MASCA \& SAITO (1979). Entretanto, em nenhum deles foram pesquisados os cultivares Crioula e Valencianita San Juan, originários de locais com latitudes diferentes das do nosso Estado.

Segundo JONES \& MANN (1963), a adaptação de cultivares é condicionada .por fatores ambientes, notadamente fotoperiodo e temperatura. Quando as condições climáticas não satisfazem às exigências do cultivar, podem ocorrer a não-bulbificação, a formação de "charuto", a emissão precoce de pendâo floral e a formação de pequenos bulbos (MASCARENHAS, 1980). Ao dilatar ou antecipar a época de semeadura, portanto, é preciso levar em consideração o cultivar, o fotoperíodo e a temperatura.

Thompson \& Smith, citados por JONES \& MANN (1963), demonstraram que a bulbificação da cebola é determinada pela interação do fotoperíodo e temperatura. Esta, por sua vez, além de influir no desenvolvimento e maturação do bulbo, é a principal responsável pelo florescimento prematuro, variando os cultivares consideravelmente nessa característica (JONES \& MANN, 1963).

No presente trabalho, fez-se a avaliação da produtividade e da qualidade do bulbo de duas novas introduções de cebola, semeadas em diferentes épocas, nas condições de Monte Alegre do Sul. O trabalho visou, além de 
possibilitar ao produtor opçбes com relação à utilização de novos cultivares e ao plantio em periodos mais amplos, obter dados subsidiários ao programa de melhoramento da cebola nas condiçôes paulistas.

\section{MATERIAL E MÉTODOS}

Estudou-se o comportamento dos cultivares de cebola Crioula e Valencianita San Juan, submetidos a quatro épocas de semeadura, num ensaio conduzido na Estação Experimental de Monte Alegre do Sul, a 777m de altitude, $22^{\circ} 42^{\prime}$ latitude S. e $46^{\circ} 39^{\prime}$ longitude W.

O 'Crioula', originário do Estado de Santa Catarina - latitude: 25 a $30^{\circ} \mathrm{S}$. - apresenta bulbos arredondados, com película aderente de cor amarelo-palha tendendo para marrom, e coleto grosso. O Valencianita San Juan, originário de San Juan, Argentina - latitude: 30 a $35^{\circ} \mathrm{S}$. - apresenta bulbos arredondados, com película aderente de cor amarelo-clara e coleto fino.

As épocas de semeadura estudadas foram: 19 de março, 20 de abril, 21 de maio e 23 de junho de 1982.

No periodo de ensaio, de 19 de março (1a semeadura) a 2 de dezembro (última colheita), a temperatura mínima ocorreu em julho $\left(6,4^{\circ} \mathrm{C}\right) \mathrm{e}$, a máxima, em novembro $\left(33,0^{\circ} \mathrm{C}\right)$. As temperaturas médias mensais no período (março - dezembro) foram, respectivamente, $21,5^{\circ} \mathrm{C} ; 18,6^{\circ} \mathrm{C} ; 16,5^{\circ} \mathrm{C}$; $17,6^{\circ} \mathrm{C} ; 16,6^{\circ} \mathrm{C} ; 18,1^{\circ} \mathrm{C} ; 18,8^{\circ} \mathrm{C} ; 20,5^{\circ} \mathrm{C} ; 22,8^{\circ} \mathrm{C}$.e $21,1^{\circ} \mathrm{C}$.

$O$ ensaio foi conduzido em solo tipo aluvião, unidade Moranguinho, de textura fino-areno-barrenta, segundo ROTTA et alii (1971), e sua análise química teve o seguinte resultado $\left({ }^{6}\right): \mathrm{pH}: 5,1 ; \mathrm{C} \%: 1,7 ; \mathrm{P}(\mathrm{ppm}): 40,0 ; \mathrm{K}^{+}$ $\left.\left({ }^{7}\right): 0,25 ; \mathrm{Ca}^{2+}\left({ }^{7}\right): 1,4 ; \mathrm{Mg}^{2+}\left({ }^{7}\right): 0,4 ; \mathrm{Al}^{3+}\left({ }^{7}\right): 0,3 ; \mathrm{H}^{+}\left({ }^{7}\right): 3,8 ; \mathrm{CTC}^{7}\right):$ 6,2, e V\%:33,3.

A adubação empregada por metro linear de sulco foi $1 \mathrm{~kg}$ de esterco de curral, $50 \mathrm{~g}$ de superfosfato simples, $20 \mathrm{~g}$ de cloreto de potássio e $40 \mathrm{~g}$ de sulfato de amônio. Os três primeiros adubos foram aplicados dez dias antes do plantio das mudas, e, o nitrogenado, em cobertura, em duas parcelas iguais, aos 30 e 45 dias após o transplante das mudas.

A cultura foi conduzida pelo sistema de mudas, sendo o transplante efetuado a 19 de maio, 21 de junho, 23 de julho e 26 de agosto, respectivamente para as épocas de semeadura de março, abril, maio e junho.

Adotou-se o delineamento estatístico de blocos ao acaso com parcelas subdivididas e cinco repetiçōes, sendo as parcelas representadas por épo-

${ }^{6}$ ) Análise realizada pelo Instituto Campineiro de Análise de Solo e Adubos Ltda. S/C (ICASA).

( ) e.mg/100ml de TFSA. 
cas de semeadura e, as subparcelas, por cultivares. Cada subparcela, com uma área de $4,32 \mathrm{~m}^{2}$, era constituída de seis linhas de doze plantas, espaçadas de $0,40 \mathrm{~m} \times 0,15 \mathrm{~m}$. Para a avaliação da produção, foram consideradas as quatro linhas internas de cada subparcela, no total de 40 plantas úteis, ocupando uma área de $2,40 \mathrm{~m}^{2}$.

Durante o desenvolvimento da cultura, foram feitas pulverizações semanais com inseticidas (Malathion) e fungicidas (Maneb e oxicloreto de cobre) e, sempre que necessário, capinas e irrigação por infiltração, sendo esta interrompida quinze dias antes de cada colheita. A colheita por época de semeadura foi efetuada por ocasião da seca e tombamento das ramas, nas seguintes datas, em 1982: 4 de outubro (cvs. Crioula e Valencianita San Juan, 1a época), 25 de outubro (cv. Crioula, 2a época), 3 de novembro (cv. Valencianita San Juan, 2a época), 8 de novembro (cv. Crioula, 3a época), 22 de novembro (cv. Valencianita San Juan, 3 a época) e 1 ? de dezembro (cvs. Crioula e Valencianita San Juan, 4. época. As plantas colhidas foram curadas à sombra por vinte dias; em seguida, os bulbos foram desprovidos das ramas e classificados em comerciáveis (1a, $2^{\mathrm{a}}$ e $3^{\mathrm{a}}$ ) e não-comerciáveis (múltiplos, pendoados e "charutos"). Os comerciáveis foram classificados, de acordo com o diâmetro transversal, em: de 1 a (diâmetro $>55 \mathrm{~mm}$ ), de 2 a (diâmetro entre 40 e $55 \mathrm{~mm}$ ) e de 3 a (diâmetro entre 25 e $40 \mathrm{~mm}$ ), conforme CAMPOS (1969). Após a classificação, os bulbos comerciáveis foram conta. dos e pesados, sendo os resultados expressos em porcentagem e quilograma/ hectare respectivamente. Os não-comerciáveis foram apenas contados, e o resultado expresso em porcentagem.

\section{RESULTADOS E DISCUSSÃO}

Os dados de produtividade e peso médio dos bulbos comerciáveis $\left(1^{\mathrm{a}}+2^{\mathrm{a}}+3^{\mathrm{a}}\right)$ dos cultivares Crioula e Valencianita San Juan, em função das épocas de semeadura encontram-se no quadro 1.

A análise estatística mostrou diferenças altamente significativas, pelo teste $F$, para épocas de semeadura, cultivares e interação épocas de semeadura $\mathrm{X}$ cultivares, quanto à produtividade e peso médio de bulbos comerciáveis.

Os resultados indicaram que a época de semeação afetou a produtividade e o peso médio de bulbos comerciáveis nos dois cultivares estudados. As produtividades médias dos cultivares Crioula e Valencianita San Juan, embora decrescentes, não diferiram estatisticamente entre si nas semeações de março, abril e maio, mas diferiram da de junho, que foi a mais reduzida. Esses resultados concordam em parte com as observações efetuadas por PRADO (1958), relatando que a produção da cebola decresce nas semea- 
ções de abril, sendo muito mais reduzida nas de maio. No presente experimento, foram obtidas produtividades satisfatórias para os dois cultivares estudados, nas semeaçôes de março, abril e maio, não se notando, pois, redução significativa na de maio. Essa aparente contradição com as observações de PRADO (1958) pode estar relacionada com o cultivar utilizado, condições climáticas locais ou interação de ambos os fatores.

QUADRO 1 - Produtividade e peso médio de bulbos comerciáveis obtidos no ensaio de comportamento de cultivares de cebola (Allium cepa L.) em diferentes épocas de semeadura na região de Monte Alegre do Sul (SP) ${ }^{1}{ }$ )

$\begin{array}{ccc}\begin{array}{c}\text { Épocas de } \\ \text { semeadura }\end{array} \quad \text { Cultivares } & \begin{array}{c}\text { Produtividade de } \\ \text { bulbos comerciáveis }\end{array} & \begin{array}{c}\text { Peso médio de } \\ \text { bulbos comerciáveis }\end{array}\end{array}$

\begin{tabular}{|c|c|c|c|c|c|}
\hline \multirow{3}{*}{ Março } & & \multicolumn{2}{|c|}{$\mathrm{kg} / \mathrm{ha}$} & \multicolumn{2}{|c|}{ g/bulbo } \\
\hline & & \multicolumn{2}{|c|}{$16.212 \mathrm{a}\left({ }^{2}\right)$} & \multicolumn{2}{|l|}{122,50 a $\left({ }^{2}\right)$} \\
\hline & $\begin{array}{c}\text { Crioula } \\
\text { Valencianita San Juan }\end{array}$ & & $\begin{array}{l}19.826 \mathrm{a}\left({ }^{3}\right) \\
12.598 \mathrm{~b}\end{array}$ & & $\begin{array}{l}151,78 \mathrm{a}\left({ }^{3}\right) \\
93,23 \mathrm{~b}\end{array}$ \\
\hline \multirow[t]{2}{*}{ Abril } & & $15.676 \mathrm{a}$ & & \multicolumn{2}{|l|}{$111,47 \mathrm{a}$} \\
\hline & $\begin{array}{c}\text { Crioula } \\
\text { Valencianita San Juan }\end{array}$ & & $\begin{array}{l}20.709 a \\
10.644 b\end{array}$ & & $\begin{array}{r}129,28 \mathrm{a} \\
93,67 \mathrm{~b}\end{array}$ \\
\hline \multirow[t]{2}{*}{ Maio } & & $13.119 \mathrm{a}$ & & \multicolumn{2}{|l|}{$85,36 \mathrm{~b}$} \\
\hline & $\begin{array}{c}\text { Crioula } \\
\text { Valencianita San Juan }\end{array}$ & & $\begin{array}{l}13.992 \mathrm{a} \\
12.246 \mathrm{a}\end{array}$ & & $\begin{array}{l}90,34 \text { a } \\
80,38 \text { a }\end{array}$ \\
\hline \multirow[t]{2}{*}{ Junho } & & $7.804 \mathrm{~b}$ & & \multicolumn{2}{|l|}{$51,42 \mathrm{c}$} \\
\hline & $\begin{array}{c}\text { Crioula } \\
\text { Valencianita San Juan }\end{array}$ & & $\begin{array}{l}8.884 \mathrm{a} \\
6.723 \mathrm{a}\end{array}$ & & $\begin{array}{l}56,66 \text { a } \\
46,17 \text { a }\end{array}$ \\
\hline \multirow{4}{*}{\multicolumn{2}{|c|}{$\begin{array}{ll}\mathrm{F} & \text { (Épocas) } \\
\mathrm{F} & \text { (Cultivares) } \\
\mathrm{F} & \text { (Épocas X Cultivares) } \\
\Delta & 5 \% \text { (Épocas) }\end{array}$}} & $25,00 * *$ & & \multicolumn{2}{|l|}{$116,14^{* *}$} \\
\hline & & & $49,58 * *$ & & $52,28 * *$ \\
\hline & & & $7,19 * *$ & & $8,60^{* *}$ \\
\hline & & 4.151 & & 15,84 & \\
\hline \multirow{2}{*}{\multicolumn{2}{|c|}{$\begin{array}{l}\text { CV (\%) (Épocas) } \\
\text { CV (\%) (Cultivares) }\end{array}$}} & 18,42 & & \multicolumn{2}{|l|}{12,51} \\
\hline & & & 18,02 & & 16,90 \\
\hline
\end{tabular}

( $\left.{ }^{1}\right)$ Média de cinco repetiçōes. $\left({ }^{2}\right)$ Letras não comuns entre as médias, relativas às épocas, indicam diferenças significativas pelo teste de Tukey a $5 \% .\left({ }^{3}\right)$ Letras não comuns entre as médias, relativas aos cultivares dentro de épocas, indicam diferenças significativas pelo teste $\mathrm{F}$ a $1 \%$. 
Entretanto, o efeito das épocas de semeadura foi mais evidente em relação ao peso médio de bulbos comerciáveis apresentados pelos dois cultivares, sendo que, nesse aspecto, as épocas de sęmeação de março e abril, sem diferirem entre si, mostraram ser melhores que as de maio e junho. A semeação de maio, por sua vez, proporcionou bulbos significativamente mais pesados que os obtidos na de junho. Observações de campo mostraram que o crescimento das plantas foi menor quando a semeação se fez em junho, havendo então uma diminuição acentuada no ciclo da cultura. Esse fato pode estar relacionado à ocorrência de temperaturas mais elevadas durante a fase de formação dos bulbos, ocasionando-lhes a maturação precoce, sem o suficiente desenvolvimento da planta. Também a ocorrência de mancha-púrpura (Alternaria porri (Ell.) Cif.) foi maior nas plantas originárias da semeação de junho, mostrando-se o cultivar Valencianita San Juan mais suscetível à doença. Nota-se, assim, que um conjunto de fatores contribuiu para reduzir a produtividade e o peso médio de bulbos obtidos na semeação de junho.

Estudando os cultivares dentro das épocas de semeadura, observouse que o 'Crioula' superou o 'Valencianita San Juan' quanto à produtividade e peso médio de bulbos comerciáveis, nas semeações de março e abril, o que não ocorreu nas de maio e junho. Isso pode ser atribuido às diferenças em adaptabilidade dos referidos cultivares às condições climáticas locais, notadamente fotoperíodo e temperatura (JONES \& MANN, 1963), que teriam afetado o desenvolvimento e a bulbificação das plantas. Convém lembrar que o 'Crioula' é originário de faixas de latitudes mais próximas das do Estado de São Paulo. A produtividade alcançada pelo 'Crioula', nas semeações de março e abril, foram $19.826 \mathrm{~kg} / \mathrm{ha}$ e $20.709 \mathrm{~kg} /$ ha respectivamente, médias estas superiores às obtidas no Estado de São Paulo $(15.799 \mathrm{~kg} / \mathrm{ha})$ em 1982 (ANUÁRIO, 1982).

Sendo a interação épocas de semeadura $X$ cultivares altamente significativa, evidenciou-se que as variedades responderam diferentemente em produtividade e peso médio de bulbos em relação às épocas de semeadura, indicando novamente que o desenvolvimento das plantas e a bulbificação da cebola são afetados pelas condições climáticas, que devem satisfazer as exigências do cultivar introduzido.

No quadro 2 os resultados da classificação por tipos de bulbos $(1$ a 2. e 3a), bulbos múltiplos, pendoados (florescimento prematuro) e "charutos", bem como o stand final e o ciclo da cultura, mostram que a obtenção de bulbos comerciáveis (tipos de $1^{\mathrm{a}}, 2^{\mathrm{a}}$. e $3^{\mathrm{a}}$ ), foram satisfatórios para os dois cultivares nas quatro épocas de semeadura.

A maior porcentagem total de bulbos comerciáveis foi alcançada pelo 'Crioula', na semeação de abril, ao passo que para o 'Valencianita San Juan' a melhor época foi maio. Não houve formação de bulbos tipo conserva (diâmetro $<25 \mathrm{~mm}$ ). 


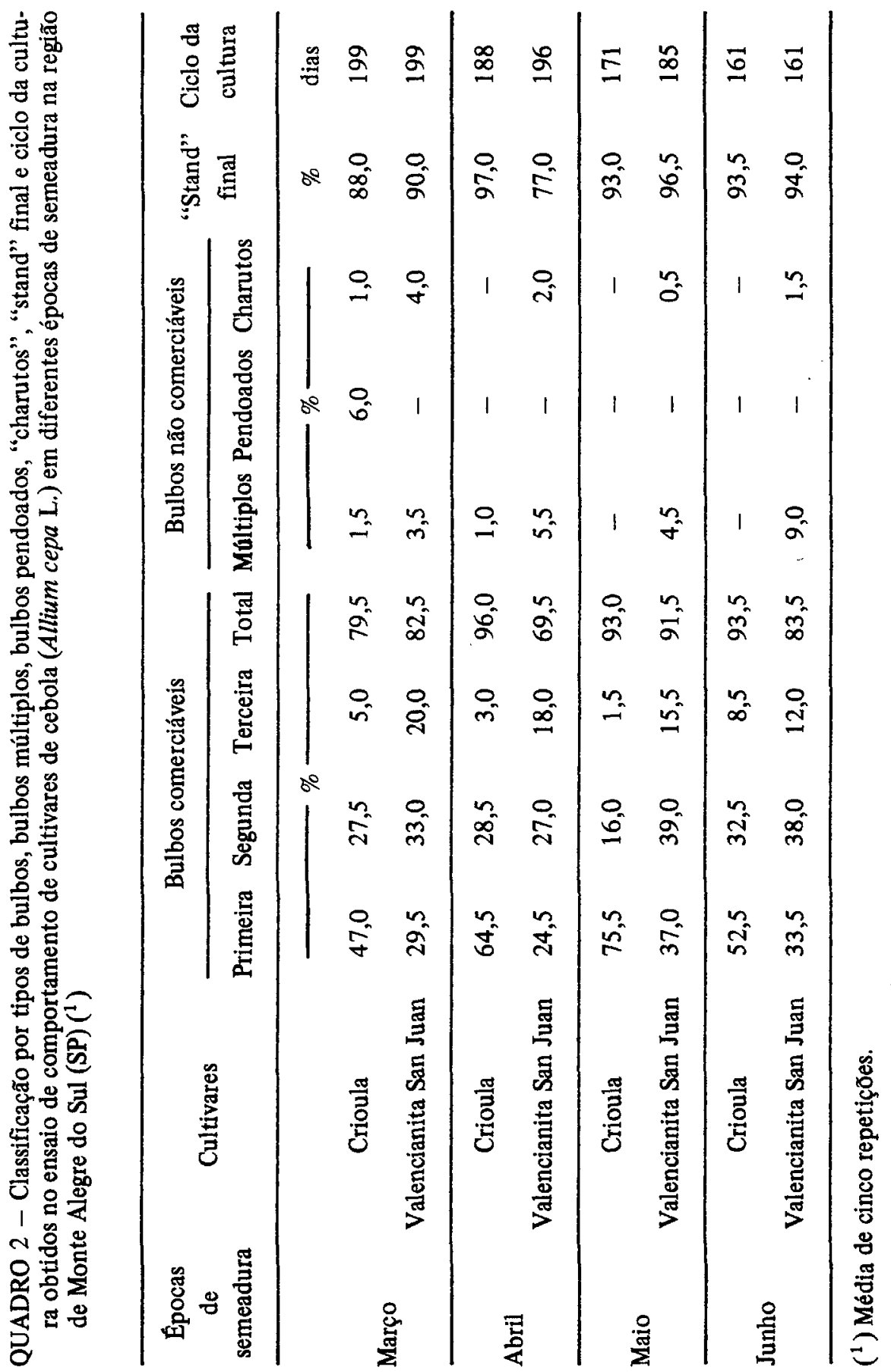


No 'Valencianita San Juan', houve produção sensivelmente maior de bulbos múltiplos, cuja porcentagem aumentou à medida que se atrasou a semeação, chegando a $9 \%$ na de jünho. Isso indica sua deficiência na adaptabilidade às condições climáticas de Monte Alegre do Sul, no ano do experimento.

A produção de bulbos com florescimento prematuro ("bolting"), foi característica do 'Crioula', ocorrendo esse fenômeno somente na semeação de março.

A porcentagem de bulbos "charutos" foi maior no "Valencianita San Juan', aparecendo em todas as épocas de semeadura, o que indica também menor adaptabilidade do material.

Para os dois cultivares, verificou-se a diminuição do ciclo da cultura à medida que se atrasou a semeação, concordando com os dados obtidos por PRADO (1958), e indicando haver influência da temperatura na maturação dos bulbos de cebola.

\section{CONCLUSOES}

Os resultados obtidos nas condições experimentais de Monte Alegre do Sul, em 1982, permitiram chegar às seguintes conclusões:

a) Nos dois cultivares estudados, houve formação de bulbos, quando semeados no periodo de 19 de março a 23 de junho. Verificou-se, no entanto, o encurtamento do ciclo da planta, à medida que se atrasou a semeação;

b) O cultivar Crioula apresentou maior produtividade e peso médio de bulbos comerciáveis, nas épocas de semeação de março e abril, não diferindo do 'Valencianita San Juan' nas de maio e junho;

c) Considerando todas as características estudadas (produtividade, peso médio de bulbos comerciáveis, produção de bulbos múltiplos, pendoados e "charutos"), abril foi a época mais propícia para a semeação do 'Crioula' e, maio, para o 'Valencianita San Juan';

d) $\mathrm{O}$ 'Crioula' apresentou melhor adaptabilidade e maior tolerância à doença mancha-púrpura, sendo mais apropriado ao cultivo nas condições ecológicas de Monte Alegre do Sul;

e) Optando-se pela utilização do 'Crioula', existem perspectivas de dilatação do período de cultivo da cebola, na região em apreço. 


\title{
SUMMARY \\ EVALUATION OF ONION'(ALLIUM CEPA L.) CULTIVARS, AT DIFFERENT SOWING TIMES, IN MONTE ALEGRE DO SUL, STATE OF SÃO PAULO, BRAZIL
}

\begin{abstract}
An experiment was carried out at Estação Experimental de Monte Alegre do Sul, State of Sāo Paulo, Brazil (22042'S), in order to evaluate two new introductions of onion (Allum cepa L.), cvs. Crioula and Valencianita San Juan. The sowing times were March, April, May and June. Results showed that there was influence of the sowing time on the yield and marketable bulb average weight of both cultivars. The yield of cv. Crioula was greater than that of cv. Valencianita San Juan on March and April sowings, but not on those of May and June. The same was observed in relation to the bulb average weight. Considering the type of bulbs and percentage of bolting, it was concluded that April is the best sowing time for cv. Crioula under the climatic conditions of Monte Alegre do Sul. It was also observed that the cycle of both cultivars was shortened by delaying the sowing date; however if the delay is too long small plants and consequently small bulbs will be formed.
\end{abstract}

Index terms: onion; Allium cepa L.; cultivars; sowing times.

\section{REFERENCIAS BIBLIOGRÁFICAS}

ANUÁRIO ESTATISTICO DO BRASIL. Rio de Janeiro, Fundação Instituto Brasileiro de Geografia e Estatística, v.43, 1982.

BIANCHI, P.C.A. Semeação de Cebola. Chácaras e Quintais, São Paulo, 106(6): 742, 1962.

CAMPOS, H.R. de. Instruções para a cultura da cebola. 2.ed. Campinas, Instituto Agronômico, 1969. 28p. (Boletim, 164)

; ROCHA, T.R. da; CRUZ, L.S.P. \& IGUE, T. Comportamento de variedades de cebola (Allium cepa L.) em três municípios do Estado de São Paulo. Campinas, Instituto Agronômico, 1969. 1p. (mimeografado) Trabalho apresentado na 9? Reunião Anual da Sociedade de Olericultura do Brasil. Goiânia, 1969.

\& ALVES, S. Competição de cultivares de cebola no município de Campinas, Estado de São Paulo - ano 1974. Revista de Olericultura, Botucatu, 15: 145-147, 1975. (Resumo)

\& IGUE, T. Ensaio nacional de cultivares de cebola (Allium cepa L.). Revista de Olericultura, Fortaleza, 12:68-69, 1972. (Resumo)

; ROCHA, T.R. da \& IGUE, T. Competição de cultivares de cebola, no município de Mococa, Estado de São Paulo - ano 1974. Revista de Olericultura, Botucatu, 15:148-150, 1975. (Resumo)

CHURATA-MASCA, M.G.C. Comportamento de cultivares de cebola. Ciência e Cultura, São Paulo, 27(12):1343, 1975. 
CHURATA-MASCA \& SAITO, S.Y. Competição de cultivares híbridas de cebola na região de Monte Alto - SP. In: CONGRESSO BRASILEIRO DE OLERICULTURA, 19., Florianópolis, 1979. Resumos. Florianópolis, EMPASC, 1979. v.1, p.40-41.

JONES, H.A. \& MANN, L.K. Onions and their Allies. Botany, Cultivation and Utilization. New York, Interscience publishers, Inc., 1963. 286p.

MASCARENHAS, M.H.T. Cultivares de cebola. Informe Agropecuário, Belo Horizonte, 6(62):17-20, 1980.

PRADO, O. de T. Instruções para a cultura da cebola. Campinas, Instituto Agronômico, 1958, 29p. (Boletim, 103)

ROTTA, C.L.; JORGE, J.A.; OLIVEIRA, J.B. de \& KÜPPER, A. Levantamento pedológico detalhado da Estação Experimental de Monte Alegre do Sul, SP. Bragantia, Campinas, 30:215-276, 1971. 